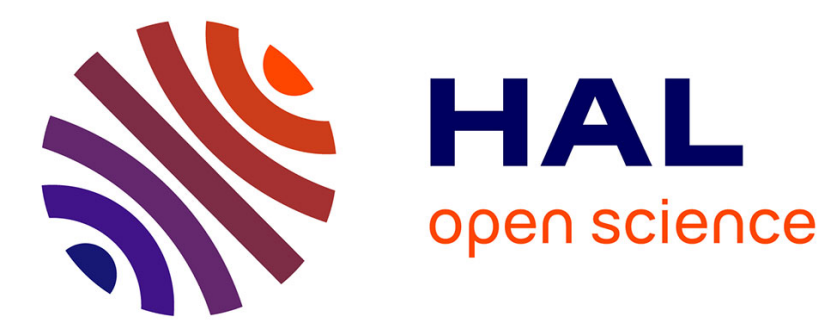

\title{
Static and Dynamic Processing of Intractable ArFRP Laminates
}

\author{
T. Nojima, K.-I. Sakaguchi
}

\section{To cite this version:}

T. Nojima, K.-I. Sakaguchi. Static and Dynamic Processing of Intractable ArFRP Laminates. Journal de Physique IV Proceedings, 1997, 07 (C3), pp.C3-61-C3-66. 10.1051/jp4:1997313 • jpa-00255416

\section{HAL Id: jpa-00255416 https://hal.science/jpa-00255416}

Submitted on 1 Jan 1997

HAL is a multi-disciplinary open access archive for the deposit and dissemination of scientific research documents, whether they are published or not. The documents may come from teaching and research institutions in France or abroad, or from public or private research centers.
L'archive ouverte pluridisciplinaire HAL, est destinée au dépôt et à la diffusion de documents scientifiques de niveau recherche, publiés ou non, émanant des établissements d'enseignement et de recherche français ou étrangers, des laboratoires publics ou privés. 


\title{
Static and Dynamic Processing of Intractable ArFRP Laminates
}

\author{
T. Nojima and K.-I. Sakaguchi* \\ Department of Aeronautics and Astronautics, Kyoto University Kyoto, 606-01, Japan \\ * Division of Mechanical Engineering, Fukui National College of Technology, Sabae 916, Japan
}

\begin{abstract}
The purpose of the present research is to develop a simple and convenient processing method of aramid composites by static as well as dynamic press workings. Under tightly restrained condition, they are processed by a specially designed hollow punch. The present improved technique named strong restraining shear processings (SRSP) has realized an excellent and convenient processing which has never been achieved by any other high technology such as water jetting.
\end{abstract}

\section{INTRODÚCTION}

Aramid fiber reinforced plastics (ArFRP) are very excellent in specific tensile strength as well as in energy absorption capacity. Though they are quite expensive under present situation, they have often been used in important parts of such vehicles as automobiles, ships and airplanes [1] [2]. Because aramid/carbon hybrid composites are extremely light, tough and strong, they will be expected to be widely used for main members of aeronautical as well as astronautical structures. However as is well known, aramid composites have been one of representative bullet-proof materials, and therefore they have been believed to be quite intractable. In fact, a lot of labourious works have been paid for achieving good finishing especially for removing many left fluffs after machining. Though aramid composites have been processed by using such high technologies as water jetting or vibration pressing in order to achieve better workability [3], it has been still quite difficult to process aramid composites of over $80 \%$ fiber in their volume fraction without any remarkable surface roughness and conspicuous left fluffs even by water jetting. The present technical situation will undoubtly wait for new, simple and economical processing technique of these materials. In order to answer the demands, one of the present authors has developed a simple processing technique for the composites based on the punching technique of engineering ceramics [4] [5].

The present report aims to introduce the punching and forming technique for aramid laminates newly developed by improving conventional press working techniques, and also aims to present its possibilities and availability in both static and dynamic processing of intractable aramid laminates.

\section{TEST MATERIAL}

Test material consists of laminated composites of plain weave $0.4 \mathrm{~mm}$ thick prereged Kevlar sheet (DuPont-Toray, $\mathrm{K}-29$; 3000 denir, averave diameter $15 \mu \mathrm{m}$ ) with matrix of polyvinyl-butylal phenol resin (volume fraction of the fibers; $90 \%$ ). 4,8 or 15 prepreged sheets was used to make laminated plates, and corresponding thickness is about $1.65,3.3$ and $6.3 \mathrm{~mm}$, respectively. Uniaxial tensile strength of the plain weave laminated plate is 500 530MPa, while the average strength of Kevlar fibers of $15 \mu$ m diameter themselves is about $3.2 \sim 3.3 \mathrm{GPa}$ (the fiber length; 100mm). The maximum elongation of the fiber is $2.5 \sim 4 \%$, and they break in perfectly brittle manner [6]. The elastic modulus of $4 \sim 8$ laminated plate is $32 \sim 35 \mathrm{GPa}$ in tension, and that in thickness direction is $0.9 \sim 1.5 \mathrm{GPa}$ in copmpression tests depending on plate thickness. 


\section{TESTING METHOD}

Newly developed quasi-static processing works were fundamentally carried out under tightly restrained condition. Figure 1 shows the clamping apparatus of an aramid sample, which was originally manufactured for the punching works in engineering ceramic plates [5]. The apparatus consists of steel frames and struts, and a commercial compact jack. After an aramid plate is set between a die and a clamping plate, the aramid plate is tightly clamped by the jack (max. load: $49 \mathrm{KN})$. Punching or forming works were performed by loading the top of a punch in a conventiona] testing machine (Simazu AG2000), and the working load $P$-displacement $\delta$ relations were directly measured by $X-Y$ plotter of the machine. Punching works of hole diameter $D=10 \mathrm{~mm}$ were systematically performed by using 3 kinds of punches depicted in Figure 2. Figure 2-(A) and (B) show conventional flat and blunted conical punches, respectively. By using these punches, mechanical behaviours during punching works were carefully investigated. In Figure 2-(C), a hollow punch is illustrated. The punch was specially designed for punching works of aramid laminates based on the punching results by using the conventional flat and conical punches. All of these punches were made of $0.45 \% \mathrm{C}$ steel and the top of the punches was quenched. In the newly developed punching method by the hollow punch, a back plate was installed to restrain the aramid laminates even at its rear face. The back plate plays a quite important role to chop away fine fibers which always remained as fluffs in the processings of aramid composites. Various kinds of materials were examined whether they are available for the back plate. They are $1 \mathrm{~mm}$ thick toughened $\mathrm{Zr}$ plate,1 $\mathrm{mm}$ thick steel plate, 3 and $10 \mathrm{~mm}$ thick PMMA plate or $1.2 \mathrm{~mm}$ thick Duralumin plate. In order to investigate the processing possibility of the developed method, punching works of such modified shaped holes as non-circular and hexagon shaped ones were also carried out. Blanking works of 1 laminates were also performed to make disc specimens ( $D=18 \mathrm{~mm})$ for impact punching test by using $3 \mathrm{~mm}$ thick PMMA back plate.

Impact punching and forming (blanking) tests were performed in a split Hopkinson pressure bar (the bars are steel made and the diameter is $20 \mathrm{~mm}$, Figure $3-(\mathrm{A})(\mathrm{B})$ ). In the tests, disc specimens were tightly clamped at the end surface of the output bar by a screwed cup with a $3 \mathrm{~mm}$ thick PHWH or $1.2 \mathrm{~mm}$ thick Duralmin back plate. In these tests, metal tools shown in Fig. 2 (D) and (E) were used and the die was installed at the end of the output bar in punching works, while in blanking works a flat anvil was used. In the impact tests, it was very sensitive to protect the edge of the tools, because surplus impact energy of ten injured them. Therefore such thin and soft materials mentioned above were chosen for the back plate, and a cylindrical Duralumin chock is also installed between punch and die (anvil).

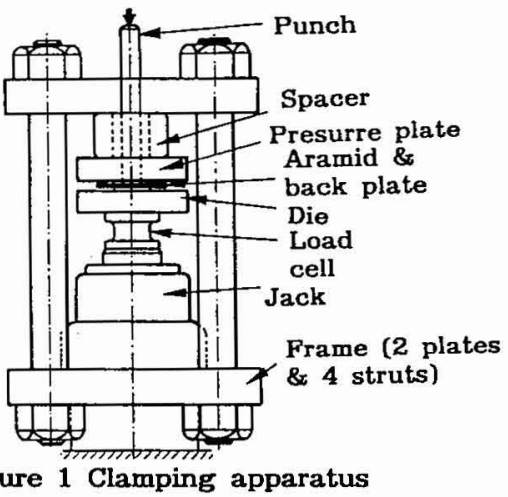

(A)

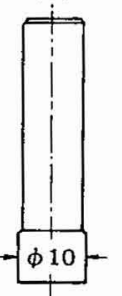

(B)

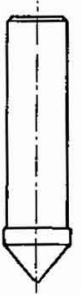

(C)

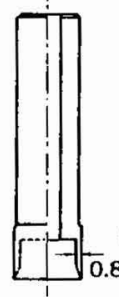

(D)

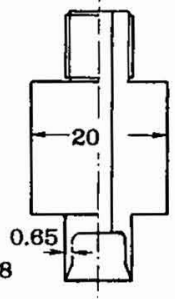

(E)

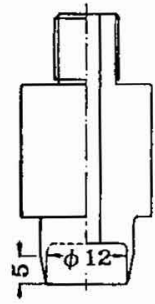

Figure 2 Top shapes of used punches, $(A)(B)(C)$; Flat, brunted conical and hollow punches,(D)(E); for impact tests ((D);punching, (E); blanking)

(A) Aramid composites Back plate
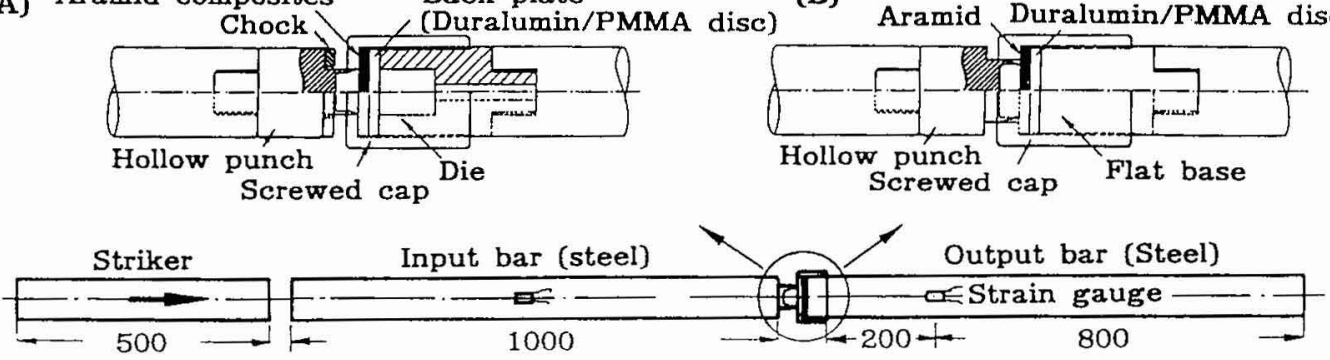

Figure 3 Experimental setup of punching (A) and blanking (B) processing in SHPB 


\section{EXPERIMENTAL RESULTS}

\section{1 Static and dynanic conventional punching tests.}

In order to clarify mechanical behaviours during punching and also to investigate difficulties in the processings, some preliminary quasi-static and dynamic punching works were performed by using conventional punches (Figure 1-(A) (B)). Because aramid laminates are very flexible, they were deformed remarkably showing a bawl-like shape by the punching load. By the deformation, serious flange wrinkles were generated around punched region, and the wrinkles consequently brought interlaminar delaminations and serious damages. Continuous loading produced crunches between die and punch, and they were of ten injured. In order to avoid such serious punching situation, aramid plates were clamped tightly by the apparatus shown in Figure 1 . Figire 4-(A) shows typical $P-\delta$ relation of the punching test by flat punch with clamping stress $\sigma c=150 \mathrm{MPa}$. Rear view of punched plate (4 laminates) is shown in Figure $5-(A)$. This punching method is quite similar to the conventional precision shear punching technique in metals, and so that a good performance will be exected. However it became clear that not only imcompletely chopped strong fine fibers can easily escape to the gap between die and punch, but also serious damages appear around punched region. Fig. $4-(B)$ shows $P-\delta$ relation for the conical punch, and the corresponding rear-view of the punched plate is shown in Figure 5-(B). No remarkable improvement was achieved either in the eradication of imcompletely chopped fibers or in the repression of damages. These results indicate that drastic improvement has not been expected by these convent inal punching technique even under tightly restrained condition. Figure $4-(C)$ shows $P-\delta$ relation by the newly developed hollow punch. Although this punch achieved conspicuous decrease in the working load, imcompletely chopped fine fibers still remained arond punched region (Figure 5-(C)).

Figure 6 shows impactly punched aramid disc-samples by the conical and hollow punches, respectively. Punching results show the same trend as the one in quasi-static, and they are also unsatisfactry for engineering use. Especially in the punching works by the conical punch, the die and the punch seriously crunch with each other and the aramid is heavily torn off. This miserable remains will make us imagine the bullet-proof ability of aramid composites.

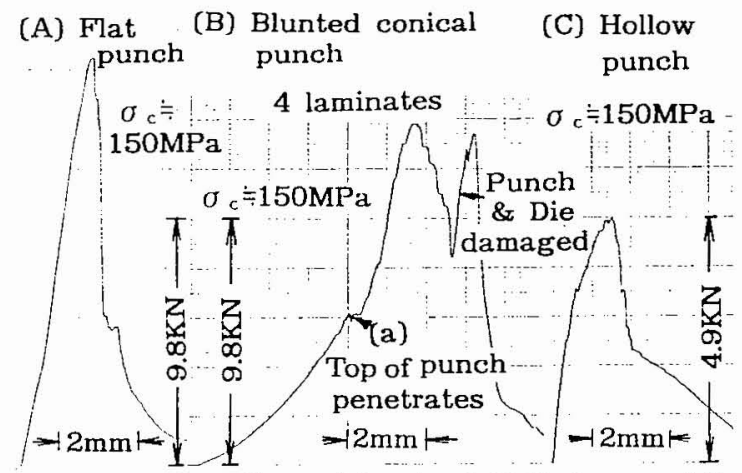

Figure 4 Quasi-static working load $P$-displacement $\delta$ curves in conventional punching works under $\sigma_{C}=150 \mathrm{MPa}$

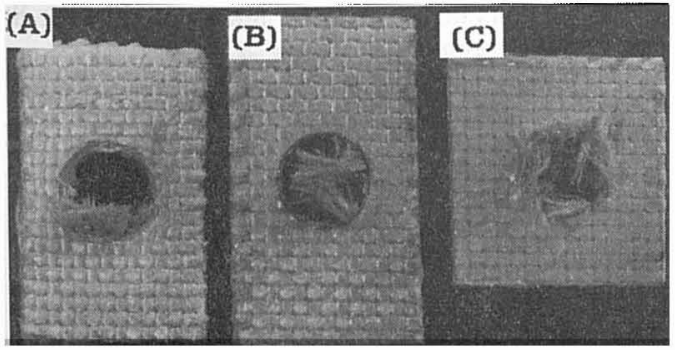

Figure 5 Punched aramid laminates (each corresponds to Figure 4)

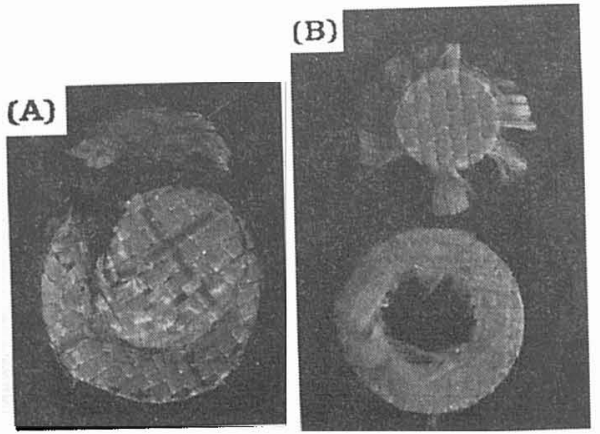

Figure 6 Punched aramid discs by conical punch (A) and hollow punch (B) $(V=10 \mathrm{~m} / \mathrm{s})$ 


\subsection{Punching and Blanking Morks by Strong Restraining Shear Processing}

In the punching works by conventional flat or conical punch, punching loads became quite large, and consequently such serious damages as pull-out of fibers and delaminations were generated if the wide rigion around punched hole. On the other hand, in the shear-type punching works with the hollow punch, al though imcompletely chopped fine fibers were remarkably left, the punching load was improved to be $30 \sim 40 \%$ of the conventional punching. In shear type punching works, it has bec: analytically proved that the radial stress $\sigma_{r}$ at the die edge $(r=D / 2)$ is very small [5]. This suggests that serious damages will not be generated at the circumferences of the hole. By using the shear type loading and also by introducing a new chopping-off mechanism of left fine fibers, new processing system has been developed to overcome many difficulties in conventinal punchings. The processing technique is schematically shown in Figure $7-(A)$; the newly developed punching method is based on the following idea; (1) in order to reduce the working load and to avoid pull-out of fibers, shear-type loading is selected, (2) to chop away fine fibers left around punched hole, back plate is newly installed (the back plate works as a chopping board of left fine fibers), (3) in order to repress delaminations around punched hole, the circumference of processed region is tightly clamped, and let punched refuse escape upwords inside of hollow punch. Consequently, extremely low working load is achieved, and this technique makes it possible to eradicate left fine fibers around punched hole. Because in the present processing method, the aramid composite is tightly clamped both at punched region as well as at its back, this punching technique has been named 「strong restraining shear punching (processing); SRSP」 method. In the punching works, the hollow punch is machined to have a sharp edge and the outside of the punch is finished straight1y. On the other hand, in blanking works the inside of the punch is machined straightly (Figure 7-(B)). By using these punches, swellings of laminates due to delamination are generated in the inside or the outside of the punches in punching and blanking works, respectively.

(A)

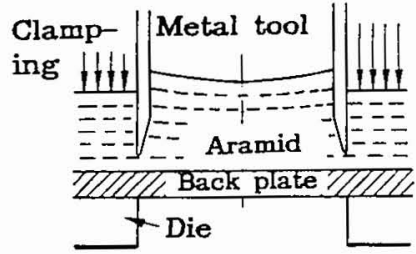

(B)

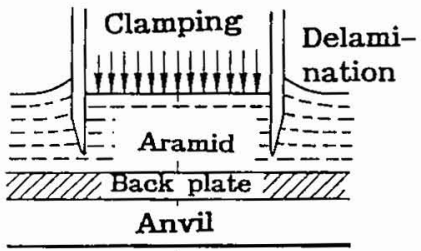

Figure 7 Punching and blanking models by SRSP method

By the SRSP method, a series of quasi-static punching and blanking works of 4 and 8 laminates were performed. A toughened $\mathrm{Zr}$ ceramic, a carbon steel, PMMA or Duralmin plate was used as the back plate. In the punching works of thin laminate plates $(1.65 \sim 3.3 \mathrm{~mm})$, no clear difference in their processed products is found in these back plates; any back plate works well as a chopping board of the left fine fibers. Examples of processed laminates are shown in Fig. 8. Figure 8-(A) shows an example of punched plate of 8 laminates by steel back plate with the clamping stress $\sigma_{\text {c }}$ $\doteqdot 150 \mathrm{MP}(D=10 \mathrm{~mm})$. As can be seen in the figure, the laminates were successfully punched $)_{u t}$. $B ;$ systematic punching works, load necessary for this punching work is roughly proportional to the diameter of the hole (i.e., shear-length) and also depends upon edge sharpness [6]. In order to prepare disc-shaped samples for impact punching tests in a split Hpkinson bar, blanking tests of $18 \mathrm{~mm}$ diameter discs were performed in $1.65 \mathrm{~mm}$ and $3.3 \mathrm{~mm}$ thick plates. The works were performed by using $3 \mathrm{~mm}$ thick PMMA back plate without restraining. In these thin plates, the work was successful. The sample of blanked discs and the corresponding punched plate is shown in Figure 8-(B).
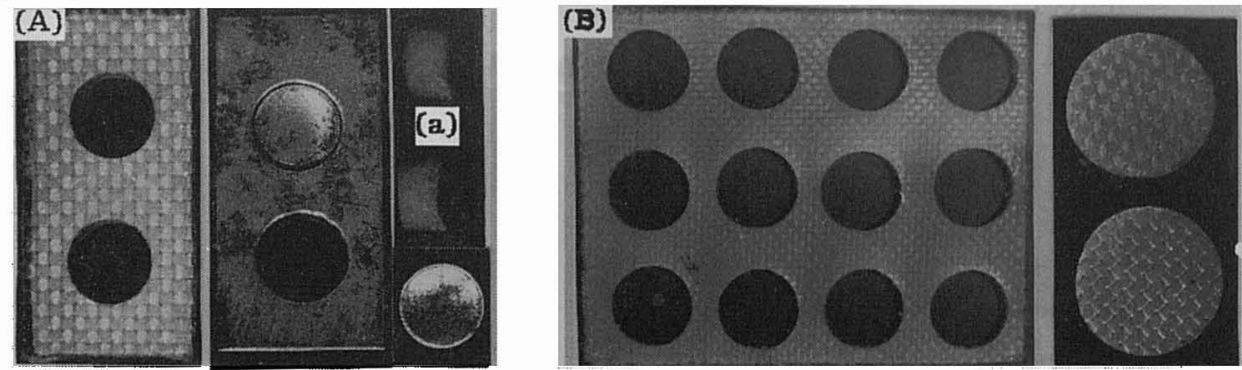

Figure 8 Examples of punched and blanked aramid laminates by SRSP (quasi-static),((A); punched 8 laminates with and without punched steel back plate and swelled punched refuse (a),(B); blanked 4 laminates and formed discs (enlarged)(for impact punching tests, D=18mm)) 


\subsection{Quasi-static and impact punching tests and rate effect on working load}

Impact punching and blanking tests were performed by the SHPB apparatus in Figure 2. In order to evaluate the rate effect on working load in the same restraining conditions, quasi-static works were also performed with the same tools used in the impact tests (Figure 9). The test samples were restrained by the screwed cap. Figure 10 shows typical $P$ - $\delta$ relations obtained by the tests. In these quasi-static works, pulsatory motions are clearly seen, and the repetitions correspond to the number of laminates. Hollow circles in Figure 10 show necessary load to make rough $\mathrm{fin}^{-}$ ishing. All of the fine fibers are not chopped completely at these loads, but some of them still remains. In order to finish the processings completely without any left fibers, slightly higher loads are necessary (solid circles). Impact punching works were performed by using thin Duralu$\min (t=1.2 \mathrm{~mm})$ and PMMA $(t=3 \mathrm{~mm})$ back plate. The punched disc specimes are shown in Figure 11. The figure shows that formability in impact works does not differ so much from static ones. However in PMMA, imcompletely chopped fibers sometimes remains (arrowed in Figure 11-(B)). Typical input and output traces by SHPB tests are shown in Figure 12 . 0btained working load $P_{\max }$-loadig velocity $V$ relations are shown in Fig. 13 . The working load $P_{m a x}$ slightly increases with V. For comparison, the $P_{\max }$ values in the punchings without back plate are shown in the same figure. The rate dependences show the same trend as those in straight cutting and the strength of fibers[6].

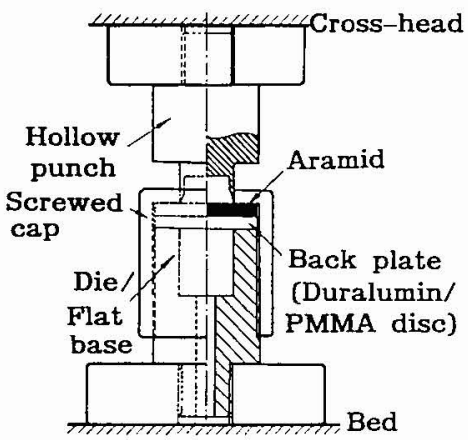

Figure 9 Punching test set-up for quasistatic tests (tools; from Figure 2-(D)(E))

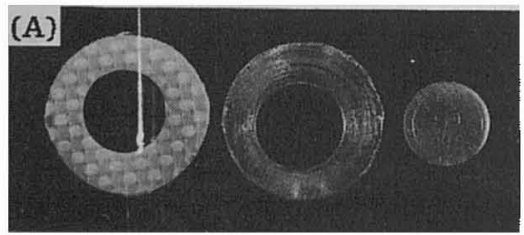

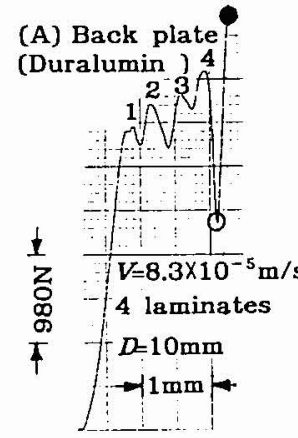

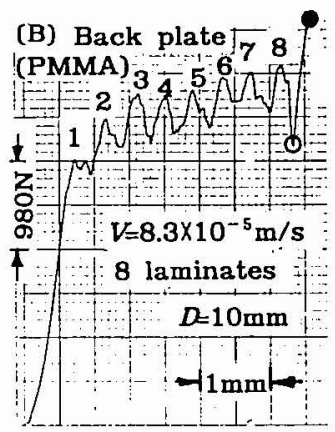

Figure 10 Typical $P-\delta$ relations showing pulsations in $P$ (quasi-static punching)

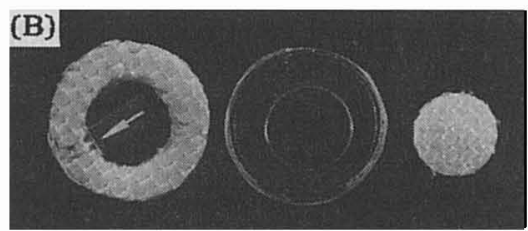

Figure 11 Photos of punched aramid 4 laminates discs by impact punching test, (A); Duralumin back plate, (B); PMMA back plate $(V=11 \mathrm{~m} / \mathrm{s})$

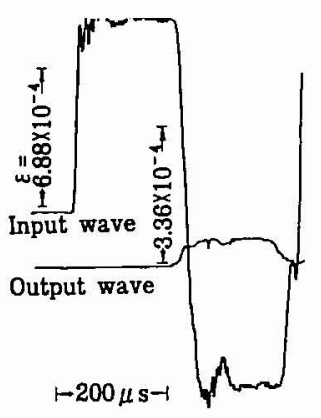

Figure 12 Typical input and output traces in impact punching

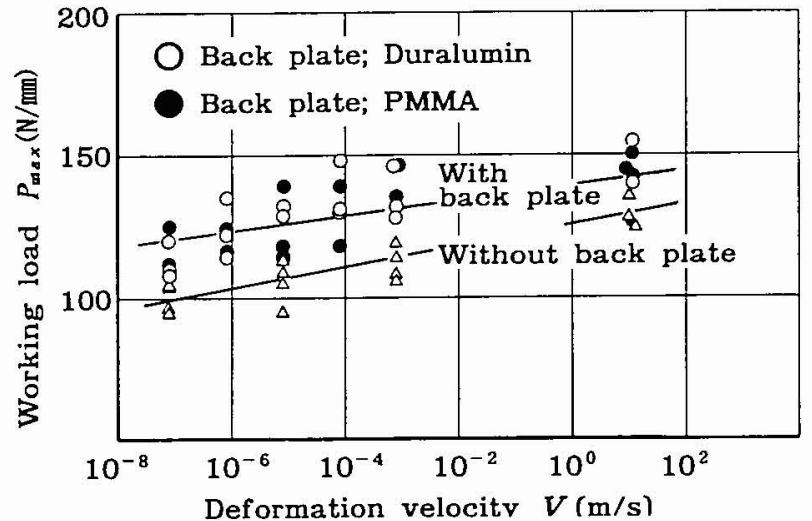

Figure 13 Loading rate effect on working load in punching works of 4 laminates(with and without back plate, $D=10 \mathrm{~mm}$ ) 

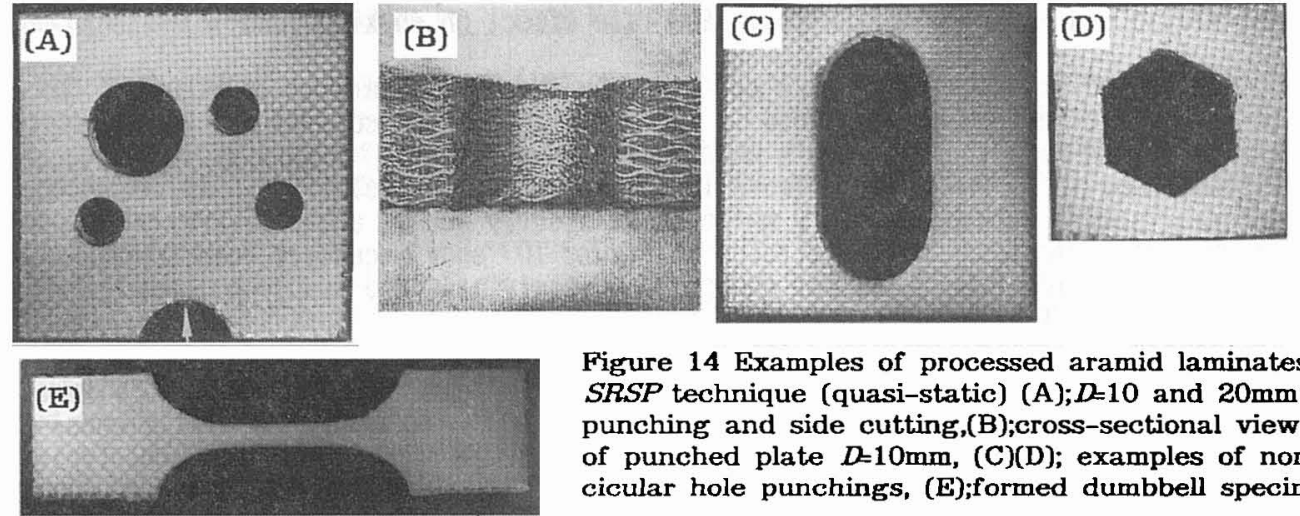

Figure 14 Examples of processed aramid laminates by $S R S P$ technique (quasi-static) (A);D=10 and $20 \mathrm{~mm}$ hole punching and side cutting,(B);cross-sectional view of punched plate $D=10 \mathrm{~mm}$, (C)(D); examples of noncicular hole punchings, (E);formed dumbbell specimen

\subsection{Availability of SRSP technique}

The availabibity of SRSP method has been investigated. Figure 14-(A) shows some examples of deep holes punched in 15 laminated composites $(t=6.3 \mathrm{~mm}, D=10$ and $20 \mathrm{~mm}$, the aspect ratios $A R=D / t$ of the holes are 1.6 and 3.2). Figure-(B) shows the cross-sectional view of the punched hole in $6.3 \mathrm{~mm}$ thick plate $(D=10 \mathrm{~mm})$. The example shows that formation of deep holes up to $A R \sim 1.6$ is possible. Figure 11-(C) and (D) show such non-circular holes as long and hexagon shaped ones punched in 8 laminates, indicating that holes in any shape can be formed. As is shown in Figure 14-(A) (bot tom side, arrowed) and Figure-(E), laminated plate can be formed from its outside. These examples suggest that simple forming processings are also possible. By these examples through the punching and forming works including the processings in thick laminates, it can be summarized that the developed SRSP technique will cover a wide range of processings of aramid composites. The developed processing will be applied directly to engineering use. Although these punching works werc only studied at low velocity range $\left(K 10^{-3} \mathrm{~m} / \mathrm{s}\right)$, it will be possible to process them at such slor impact velocity as $V \sim 10 \mathrm{~m} / \mathrm{s}$.

\section{CONCLUSIONS}

Not only by clamping tightly around punched or formed region of aramid laminates but also by restraining them from its rear face, a new processing technique of aramid plate has been developed. The developed technique has been named strong restraining shear processings (SRSP). Quasi-static and impact punching works were performed by the technique. The obtained results are summarized as follows;

(1) Circular holes can be punched out in aramid laminates (the thickness $1.6 \sim 6.3 \mathrm{~mm}$ ) without any left fine fivers around punched hole as far as the aspect ratio of the hole is larger than about 1.6. Non-circular holes can be punched out in the same manner. The finishing by the technique is quite excellent one which has never been realized,

(2) Forming works of simple shape are also possible as far as die and hollow punch can be prepared. The developed technique can be quickly used for practical applications, and they will realize quite cconomical and convienient processings,

(3) Although the working load increases as the forming velocity $V$ gets larger, the rate effect is less sensitive at $K 10 \mathrm{~m} / \mathrm{s}$. The trend is quite preferable for high speed processings in aramid laminates. By improving protection techniques of the tools, high speed processings will be available in engineering.

\section{References}

(1) Reinforced Plastics, (Dec. 1979) 400-404

(2) Pinzelli R., Reinforced Plastics, (July/Aug. 1990) 28-33

(3) Yokoi H., Nakagawa T., J. of Japan Soc. Tech. of Plasticity 25 (1984) 335-342

(4) Noj ima T., Japan Soc. Mech. Eng. (to be published) (1997)

(5) Noj ima T., Japan Soc. Mech. Eng. International C, 39 (1996) 426-431

(6) No jima T., (unpubl ished work) 